\title{
Introduction to the Art of Chemistry
}

\author{
Stefan Matile*
}

\begin{abstract}
The author describes his undergraduate and graduate studies at the University of Zurich. His interest in large complex molecules at the interface between chemistry and biology led him to Columbia University, New York and Georgetown University, Washington before he accepted a professorship at the University of Geneva.
\end{abstract}

Keywords: Institute of Organic Chemistry UZH

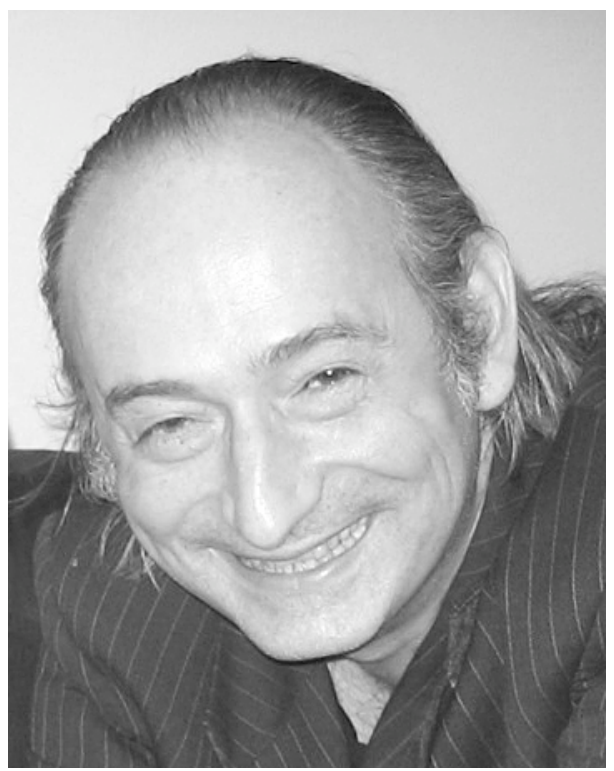

Stefan Matile
In my case, the University of Zurich was an obvious choice because I could enter without an admission exam to study chemistry. Having never thought to become a scientist, my education had had other priorities and my knowledge in science clearly below average. It was at the University where I was convinced that it was worthwhile first to catch up and then to stay and graduate in chemistry. Outstanding contributions from the many excellent teachers at that time gradually persuaded me to do so.

During my first year at UZH (1984), I remember experimental physics as exceptionally entertaining, a course that made me follow physics as a minor, until statistical mechanics in the third year was too much and biochemistry became too attractive.

Professor Salzer delivered the first-year general chemistry lectures. It came with live demonstrations that were recorded by a special assistant with a monstrous camera to make the fuming test tubes appear simultaneously on several screens in the room. The afternoons were spent on the top floor in the student labs where the most spectacular sunsets over Zurich could be enjoyed. (At that time, chemistry had already moved to the beautiful Irchel campus.)

Highlights during the next years included the following. The lectures by Professor Oswald were legendary. The inspired highspeed synthetic organic chemistry by Professor Vasella was most enjoyable. Natural products chemistry was still delivered by Professor Eugster, and stereochemistry by Professor Dreiding. No masspec fragment passed unassigned in organic spectroscopy by Professor Hesse. Professor Robinson arrived during my time and I very well recall attending his very first course offered in Zurich. Memorable of course the perfumes Professor Fràter brought to his synthesis lectures, or learning nomenclature from Dr. Volkan Kisakürek.

My first research adventure, under the careful guidance of Professor Rüedi, was to isolate organic pigments from a big mountain of dried leaves, if I remember correctly, and to measure the absorption spectrum of the pure compounds. It was a marvelous experience.

For diploma and $\mathrm{PhD}$ research, I joined the group of Professor Woggon. The PhD project focused on the preparation of catalytic antibodies with P450 activity. ${ }^{[1]}$ Professor Woggon suggested to me that I synthesize porphyrin $\mathbf{1}$ as an antigen (Fig. 1). The immune response would then produce the P450 abzymes. In the anti-1-antibodies, the central iron porphyrin with four peripheral carboxylic acids of $\mathbf{1}$ was meant to template the binding site for an iron porphyrin cofactor in the final catalyst. The disulfide bridge below the porphyrin was placed to introduce - by reductive amination from a nearby lysine followed by disulfide cleavage - an axial thiolate ligand in the final P450 abzyme. The alkoxy bridge at the other side of the porphyrin was meant to protect the iron from induced coordination from the antibody with an intramolecular ligand. The threitol centre of this bridge was also expected to template a binding site for the stereoselective hydroxylation of alkane substrates. A spectacular molecule, I thought, big and colorful!

My experience with complex porphyrins at the interface of chemistry and biology convinced Professor Nakanishi to accept me as postdoctoral fellow in his group at Columbia University in New York. My project was to explore porphyrins as reporter groups in exciton-coupled circular dichroism (ECCD) spectroscopy. [2] To explore the limit of ECCD with porphyrins, the chiral molecule between the two porphyrins grew
Correspondence: Prof. Dr. S. Matile

University of Geneva, Geneva

Tel.: +4122 3796523

Fax: +4122379 3215

E-mail: stefan.matile@chiorg.unige.ch 


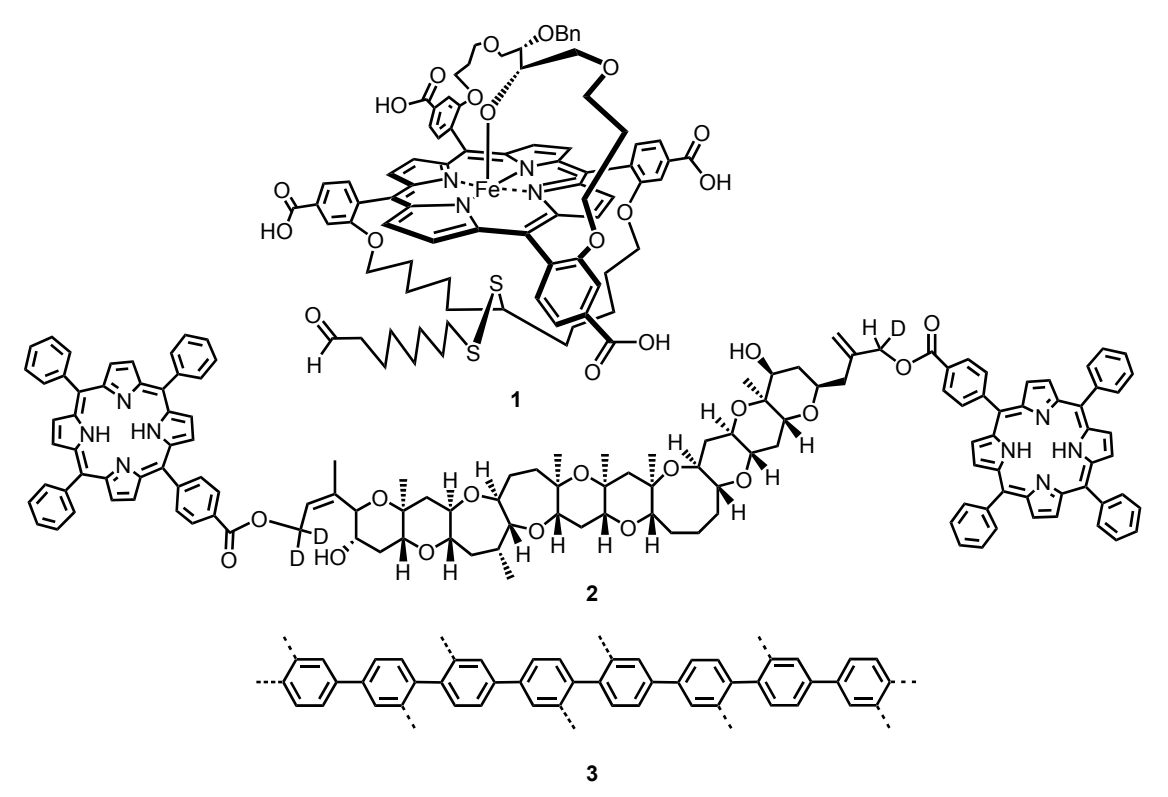

Fig. 1. From doubly-bridged iron porphyrins over brevetoxin-bridged bisporphyrins to rigid-rod molecules such as $p$-oligophenyls

longer and longer, from cyclohexyls over steroids and dimeric steroids to the brevetoxin in bisporphyrin 2 (made from a leftover of the structure determination in the early 80s in one of Koji's freezers).

The need to place two porphyrins far apart in space made me think about molecules that are linear, long, unbendable and uncompressible. When I became independent as an Assistant Professor at Georgetown University in Washington DC, I decided to forget about the porphyrins of my mentors and focus on these long and unbendable spacers. Particularly $p$-oligophenyls such as $\mathbf{3}$ were used as privileged scaffolds to synthesize big supramolecules that can do something interesting. Over the years, this approach provided access to motifs such as rigid-rod barrels, helices, stacks, slides, wires, zippers and films that can act as photosystems, pores, ion channels, sensors, catalysts, and so on. ${ }^{[3-7]}$

Asked for documents that may reflect the spirit of our time at University of $\mathrm{Zu}$ - rich, I can offer Fig. 2. Although poorly preserved, this note still decorates the walls of my current office in Geneva, maybe to keep me working on one of my most persistent problems (my colleagues say it's getting worse), maybe to occasionally refresh my sense of gratitude for the outstanding teachers and researchers at the University of Zurich that introduced me to the art of chemistry.

Received: January 21, 2008

[1] S. Matile, PhD Thesis, University of Zurich, 1994.

[2] S. Matile, N. Berova, K. Nakanishi, J. Fleischhauer, R. W. Woody, J. Am. Chem. Soc. 1996, 118, 5198-5206.

[3] N. Sakai, K. C. Brennan, L. A. Weiss, S. Matile, J. Am. Chem. Soc. 1997, 119, 8726-8727.

[4] N. Sakai, J. Mareda, S. Matile, Acc. Chem. Res. 2005, 38, 79-87.

[5] S. Bhosale, A. L. Sisson, P. Talukdar, A. Fürstenberg, N. Banerji, E. Vauthey, G. Bollot, J. Mareda, C. Röger, F. Würthner, N. Sakai, S. Matile, Science 2006, 313, 84-86.

[6] S. Litvinchuk, H. Tanaka, T. Miyatake, D. Pasini, T. Tanaka, G. Bollot, J. Mareda, S. Matile, Nat. Mater. 2007, 6, 576-580.

[7] N. Sakai, A. L. Sisson, T. Bürgi, S. Matile, J. Am. Chem. Soc. 2007, 129, 15758-15759.

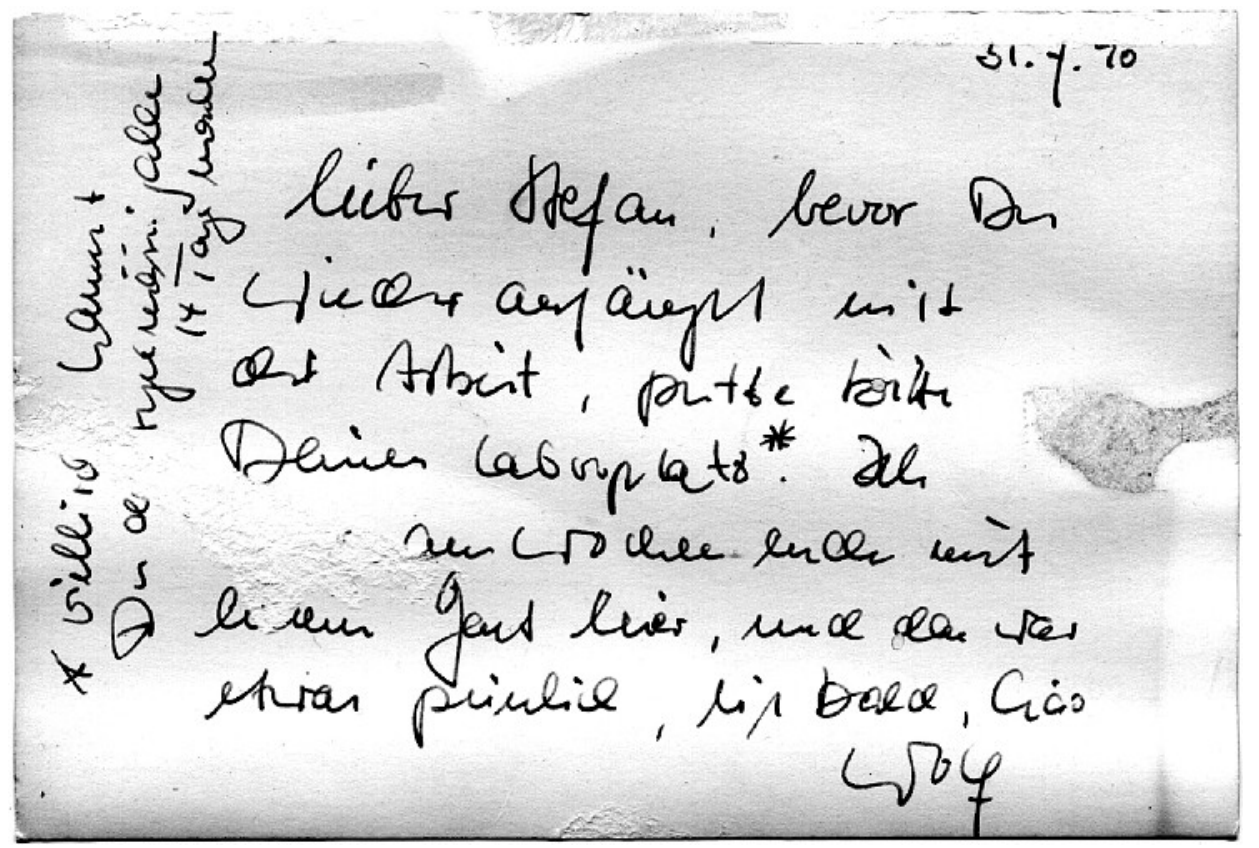

Fig. 2. Lessons from Zurich: "Dear Stefan, before you restart working, please clean your place. (Maybe you could do this regularly after 14 days.) I was here over the weekend with a guest, and it was a bit embarrassing... Wolf, 31.7.90." 